\title{
EXPRESSÃO DA ESTERILIDADE FEMININA E DA CARPELOIDIA EM MAMOEIRO SOB DIFERENTES AMBIENTES DE CULTIVO PROTEGIDO ${ }^{1}$
}

\author{
LUIZ AURÉLIO PERES MARTELLETO² , RAUL DE LUCENA DUARTE RIBEIRO ${ }^{3}$, \\ MARILUCI SUDO-MARTELLETO ${ }^{4}$, MARCO ANTÔNIO DA SILVA VASCONCELLOS ${ }^{5}$, \\ MAURÍCIO BALLESTEIRO PEREIRA ${ }^{6}$
}

RESUMO - O presente estudo teve por objetivo avaliar a ocorrência de esterilidade feminina e de carpeloidia em mamoeiros hermafroditas 'Baixinho-de-Santa Amália' cultivados sob manejo orgânico, em diferentes tipos de ambiente de proteção,e conduzido com ou sem bifurcação do tronco no transcorrer das quatro estações do ano. Foram construídos três tipos de estruturas de proteção contíguas: (i) estufa (cobertura de plástico); (ii) estufa sombreada (cobertura adicional de tela 'sombrite' $-30 \%$ sobre o plástico), e (iii) telado (cobertura exclusiva de tela 'sombrite' $-30 \%$ ), ao lado de uma área de ambiente natural, a pleno sol. Nestes locais, foram cultivados, dentro das normas técnicas da agricultura orgânica, mamoeiros da cv. Baixinhode-Santa-Amália. Em metade das plantas, abrangendo todos os ambientes de cultivo, a gema apical foi incisada, logo após a sexagem, visando à bifurcação do tronco. Para efeito de análise de variância, foram considerados quatro blocos por ambiente de cultivo, tendo cada bloco três repetições relativas ao modo de condução das plantas (com e sem bifurcação do tronco). Para análise estatística, procedeu-se à "análise conjunta de experimentos", no caso, os ambientes de cultivo. Nos mamoeiros com tronco bifurcado, houve diminuição do número de frutos carpeloides e aumento do número de flores fêmeas estéreis. No entanto, essa bifurcação não influenciou a frequência de frutos normais. Durante a primavera (setembro a dezembro), e notadamente na estufa, o maior número de frutos carpeloides por planta correlacionou-se a temperaturas mais elevadas, maior amplitude térmica e maior vigor vegetativo; já, a maior ocorrência de flores estaminadas correlacionou-se também a temperaturas elevadas, baixa luminosidade e menor vigor vegetativo. Por outro lado, essas mesmas condições ambientais e fenológicas favoráveis à carpeloidia aumentaram a quantidade de frutos normais, assim contribuindo positivamente para a produtividade do mamoeiro.

Termos para indexação: Carica papaya, agricultura orgânica, cultivo protegido, carpeloidia, esterilidade feminina.

\section{EXPRESSION OF FEMALE STERILITY AND CARPELLOIDY ON PAPAYA TREE UNDER DIFERENT ENVIRONMENTS OF PROTECTED CULTIVATION}

\begin{abstract}
This present study aimed to evaluate the occurrence of female sterility and carpelloidy on hermaphrodite papaya cv. Baixinho de Santa Amalia growing under organic management in different types of environment protection and conducted with or without bifurcation of the trunk during the course of the four seasons. Three types of structures for crop protection were built side-by-side as follows: (i) greenhouse (plastic covering), (ii) shadowed greenhouse ('sombrite' net - 30\% over the plastic sheet), and (iii) screenhouse ('sombrite' net - 30\% exclusively), in an area of natural environment, for papaya (cv. Baixinho de Santa Amália) cultivation through organic farming system. Half of the plants in all treatments were submitted, right after sex determination, to apical incision for trunk bifurcation. For purposes of analysis of variance four blocks were considered by growth environment, each block having three replicates on how to conduct plant (with and without trunk bifurcation). For statistical analysis, it was proceeded the "jointly experiment analysis" method, in this case, the environments that were planted the plants. In papaya plant with a bifurcated trunk there was a decrease in the number of carpelloid fruits and increased number of female sterile flowers. However, this fact did not affect the production of normal fruits. During spring time, and especially in the greenhouse, the largest number of carpelloid fruits per plant was correlated at higher temperatures range, thermal amplitude and vegetative growth rate. The higher occurrence of staminate flowers was also correlated to high temperatures, low light and low vegetative vigor. Nevertheless, these same conditions favored the occurrence of perfect hermaphrodite fruits, thus contributing positively to papaya yield.
\end{abstract}

Index terms: Carica papaya, organic farming, protected cropping, carpelloid fruit, female sterility.

\footnotetext{
${ }^{1}$ (Trabalho 202-10). Recebido em: 16-09-2010. Aceito para publicação em: 18-08-2011. Parte da tese de doutorado do primeiro autor. ${ }^{2}$ Prof. Adjunto Depto de Fitotecnia, Instituto de Agronomia, UFRRJ, BR 465, km, Seropédica-RJ. E-mail: martelleto@ufrrj.br ${ }^{3}$ Prof do Curso de Pós-Graduação em Fitotecnia, Depto de Fitotecnia, Instituto de Agronomia, UFRRJ, BR 465, km 07, Seropédica-RJ. E-mail: norma@cnpab.embrapa.br

${ }^{4}$ Eng. Agr.Doutoranda, Curso de pós-graduação em Fitotecnia, UFRRJ, BR 465, km 07,Seropédica-RJ. E-mail: luaumari@yahoo.com ${ }^{5}$ Prof. Associado, Depto de Fitotecnia, Instituto de Agronomia, UFRRJ, BR 465, km 07, Seropédica-RJ. E-mail: masv@ufrrj.br ${ }^{6}$ Prof. Associado, Depto de Genética da UFRRJ, BR 465, km 07, Seropédica-RJ. E-mail:balleste@ufrrj.br
} 


\section{INTRODUÇÃO}

A espécie Carica papaya L. apresenta três formas básicas de sexo: feminina, masculina e hermafrodita. A determinação do sexo é controlada por dois genes determinantes localizados num par de cromossomos sexuais primitivos (MING et al., 2007). No entanto, em mamoeiros hermafroditas, estudos sobre a fisiologia da floração registram influência marcante de fatores ambientais, tais como temperatura e umidade do ar e do solo, sobre a frequência de flores anormais, incluindo as carpeloides, pentândricas e estaminadas.

Segundo Lassoudiére (1968), o surgimento dessas variantes resulta de fatores microclimáticos prevalentes no momento da ontogenia floral. Couto e Nacif (1999) e Dantas et al. (2002) destacaram, também, que a disponibilidade excessiva de nitrogênio no solo pode condicionar deformações florais que culminam no aparecimento de frutos carpeloides ("cara-de-gato") e/ou pentândricos. No entanto, conforme já afirmaram Ronse e Smets (1999), os estudos relativos à biologia floral do mamoeiro cultivado no Brasil são restritos.

O desenvolvimento dos órgãos reprodutivos envolve um número de processos independentes, porém altamente coordenados. Usualmente, iniciase com a percepção de variação de determinado(s) fator(es) ambiental(is), o(s) qual(is) determina(m) a diferenciação celular, convergindo para a formação do primórdio floral (DEFAVARI; MORAES, 2002).

A "reversão sexual" é uma das anomalias, que ocorre em mamoeiros hermafroditas, sendo caracterizada pela atrofia do ovário, não havendo formação do fruto. $\mathrm{O}$ fenômeno é denominado de estaminação ou esterilidade feminina.

No caso da carpeloidia, ainda na fase inicial do desenvolvimento floral, alguns filetes aderem à parede do ovário, dando origem a frutos deformados, os quais não têm valor de mercado (MARIN et al., 2003). Por esta razão, em lavouras comerciais, recomenda-se desbastá-los antes do pleno desenvolvimento.

Sabe-se que o percentual de ocorrência de flores carpeloides em mamoeiro está significativamente relacionado às baixas temperaturas do ambiente de cultivo e às maiores taxas de crescimento da planta (ALMEIDA, et al.,2003). Por outro lado, temperaturas demasiadamente elevadas também influenciam no processo reprodutivo em plantas hermafroditas, provocando aumento proporcional do número de flores estaminadas (AWANDA, 1958).

Praticou-se,neste trabalho, a incisão artificial da gema apical de metade das plantas, forçando, assim, a formação de duas hastes produtivas em metade das plantas. Tal interferência teve o objetivo de verificar se este possível manejo influi nos aspectos produtivos do mamoeiro. Estudos sobre a manifestação de tipos florais em mamoeiros conduzidos na forma citada são, aparentemente, inéditos. Não foi encontrada nenhuma referência bibliográfica sobre o comportamento do mamoeiro, quando manejado dessa maneira

O presente estudo teve por objetivo avaliar a ocorrência de esterilidade feminina e de carpeloidia em mamoeiro hermafrodita 'Baixinho-de-SantaAmália' cultivado sob manejo orgânico, em diferentes tipos de ambiente de proteção e manejado com ou sem bifurcação do tronco.

\section{MATERIAL E MÉTODOS}

O estudo foi conduzido no Sistema Integrado de Produção Agroecológica - SIPA, "Fazendinha Agroecológica Km 47”, município de Seropédica, Mesorregião Metropolitana do Estado do Rio de Janeiro (latitude de $22^{\circ} 45^{`} \mathrm{~S}$, longitude de $43^{\circ} 42^{`}$ $\mathrm{W}$, altitude aproximada de $30 \mathrm{~m}$ ) (ALMEIDA et al., 1999).

Construiu-se uma estrutura tipo túnel, com 25,0 $\mathrm{m}$ de comprimento, 8,0 $\mathrm{m}$ de largura, pé-direito de $3,0 \mathrm{~m}$ e limite máximo (cumeeira) atingindo 4,5 m, coberta com polietileno de baixa densidade (PEBD) e revestida nas partes laterais e frontais com tela clarite antiafídica (malha de 0,24 mm). Em 50\% dessa estrutura, utilizou-se tela 'sombrite' $(30 \%$ de interceptação de luz) sobre o plástico, formando dois ambientes de cultivo, com dimensões de 12,5 $\mathrm{m}$ de comprimento por 8,0 m de largura. Ao lado da estrutura descrita, montou-se um telado de dimensões idênticas $(12,5 \times 8,0 \mathrm{~m})$, também com pé-direito de $3,0 \mathrm{~m}$ e revestido apenas com tela 'sombrite' $(30 \%$ de interceptação de luz). Ao lado das estruturas do cultivo protegido, o mamoeiro foi cultivado em ambiente natural (a pleno sol).

No centro de cada ambiente, a 1,80 m do nível do solo, foi colocado um termômetro de máxima e mínima, registrando-se,diariamente, a temperatura do ar. A Umidade Relativa do Ar foi registrada, diariamente, às 09 horas, através de termoigrômetros manuais digitais. Os valores das temperaturas e das umidades relativas do ar foram acompanhados durante todo o ano de estudo. Quanto à quantidade de radiação fotossinteticamente ativa, realizaram-se duas medidas, uma no inverno e outra no verão, por meio do aparelho "Portable Photosynthesis System" (IRGA - Licor 6200), durante dias de sol pleno.

Foram preparadas 24 covas em cada am- 
biente, no espaçamento de $2,0 \times 1,9 \mathrm{~m}$. As mudas da cv. 'Baixinho-de-Santa-Amália', apresentando em média $26 \mathrm{~cm}$ de altura, oriundas de sementes extraídas de mamões cultivados no SIPA, depois de 75 dias da semeadura, foram transplantadas em março de 2004. Na sexagem, que acorreu de 42 a 57 dias após o transplante (DAT), eliminaram-se as plantas fêmeas, mantendo-se uma única planta hermafrodita em cada cova.

Em 50\% dessas plantas selecionadas, obedecendo ao modelo experimental adotado, a gema apical foi incisada, 62 DAT, visando à bifurcação do tronco. $\mathrm{Na}$ operação, usou-se um canivete inoxidável, para efetuar-se um corte vertical, com aproximadamente três $\mathrm{cm}$, dividindo a gema apical ao meio. $\mathrm{O}$ canivete foi sanitizado, depois da operação em cada planta, pelo uso de água sanitária a 3\%.

As ervas espontâneas emergidas no interior do plantio foram controladas por meio de cobertura morta (palha) e de roçadas periódicas. As irrigações foram efetuadas com mangueira plástica, evitandose atingir a parte aérea das plantas e buscando-se máxima uniformidade entre os tratamentos, além de não permitir estresse hídrico ao longo da execução dos experimentos.

As plantas foram mensalmente adubadas com "cama" de aviário (1,51/cova) e bimensalmente com sulfato de potássio $\left(50 \mathrm{~g} \mathrm{cova}^{-1}\right)$. Pulverizações quinzenais foram procedidas alternando o biofertilizante Agrobio (FERNANDES, 2000) e calda bordalesa, ambos formulados na Estação Experimental de Seropédica (Pesagro-Rio).

Para determinar o nível de manifestação de cada tipo floral nos mamoeiros hermafroditas, desde o mês de junho de 2004, coletou-se e contou-se, semanalmente, o número de flores estaminadas e de frutos carpeloides e normais abortados em cada planta, e computou-se, ainda, no final de cada mês, o número de frutos carpeloides aderidos às plantas, descartando-os. Os frutos normais, surgidos no decorrer de cada mês de cultivo, foram também contabilizados. Essas determinações ocorreram até cumprir-se um ano do ciclo do mamoeiro, envolvendo a totalidade das plantas que compunham o estande experimental. Para efeito de correlação, mensalmente, contou-se o número de folhas emitidas pela planta a cada mês; a quantidade de folhas presentes por planta em cada avaliação mensal; estimou-se a área foliar pela folha-índice (folha-íntegra, tendo atingido o máximo crescimento e contendo naquele momento a primeira flor em antese na axila) e mediram-se a altura da planta e o diâmetro do tronco no local da emissão floral.

Para efeito de análise de variância, foram considerados quatro blocos por tratamento (ambiente de cultivo), com três Unidades Experimentais (UE), referentes ao modo de condução das plantas (com e sem bifurcação do tronco), em cada bloco. Foram utilizados os testes de normalidade da distribuição dos erros, propostos por Lilliefors, de homogeneidade da variância, proposto por Cochran, conforme Steel e Torrie (1980), concernentes às variâncias dentro de cada tratamento, procedendo-se, em seguida, à "análise conjunta dos experimentos", conforme metodologia preconizada por Pimentel-Gomes (2000).

\section{RESULTADOS E DISCUSSÃO}

Os dados analisados ajustaram-se à distribuição normal (pelo teste de Lilliefors) e apresentaram homogeneidade de variâncias (teste de Cochran), permitindo assim a realização da análise de variância conjunta, aplicando-se o teste de Tukey $(\mathrm{p}<0,05)$. Pelos resultados apresentados na Tabela 1 , nota-se que apenas nos meses de setembro e outubro de 2004 e de fevereiro de 2005 houve efeito significativo do modo de condução da planta de mamoeiro sobre o número total de frutos carpeloides, havendo também, a partir do mês de novembro de 2004 até maio de 2005, efeito sobre o número total de flores estaminadas por planta.

Em termos médios anuais, a bifurcação do tronco diminuiu em $41,4 \%$ a ocorrência de frutos carpeloides e aumentou em cerca de $77 \%$ a ocorrência de flores estaminadas.

A maior incidência de frutos carpeloides, chegando a mais de três planta ${ }^{-1} / \mathrm{mês}^{-1}$ correspondeu às plantas não incisadas, por ocasião da primavera (meses de setembro e novembro), época em que se verificou máxima quantidade de frutos abortados. Já, a frequência mais alta de frutos carpeloides que permaneceram aderidos às plantas foi durante o mês de abril de 2005 (Figura 1).

Considerando as médias anuais, houve diferença significativa entre os ambientes de cultivo, tanto para número de flores estaminadas quanto para frutos carpeloides e normais produzidos por planta (Tabela 2). Mensalmente, ocorreu maior quantidade de frutos carpeloides na estufa (cerca de 42 frutos por grupo de 10 plantas $/ \mathrm{mês}^{-1}$ ) do que no telado, cuja média se situou próxima a dois frutos por 10 plantas/ mês ${ }^{-1}$. A estufa sombreada e o ambiente natural praticamente se igualaram na manifestação da referida anomalia, com médias de seis e oito carpeloides por 10 plantas $/ \mathrm{mês}^{-1}$, respectivamente.

Quanto à manifestação de flores estéreis, notou-se na estufa sombreada máxima ocorrência, com média mensal de 18,2 flores estaminadas plan- 
$\mathrm{ta}^{-1} / \mathrm{mês}^{-1}$, representando quase $60 \%$ a mais do que no ambiente natural de cultivo, onde ocorreram, em média, 11,4 destas flores planta ${ }^{-1} / \mathrm{mês}^{-1}$. Na estufa e no telado, por sua vez, não se diferenciaram do ambiente natural quanto à frequência de flores fêmeas estéreis. Independentemente do modo de condução das plantas, o aumento da ocorrência dessa anomalia coincidiu com a época do ano de temperaturas mais elevadas, corroborando registros anteriores feitos por Costa e Pacova (2003).

Com relação à produção de frutos normais nos diferentes ambientes de cultivo, a maior frequência mensal, para a maioria das épocas, ocorreu na estufa (média de 15,6 frutos planta ${ }^{-1} / \mathrm{mês}^{-1}$ ), superando o ambiente natural de cultivo (média de 9,8 frutos planta $\left.^{-1} / \mathrm{mês}^{-1}\right)$. A menor ocorrência foi registrada no telado (média de 7,1 frutos planta ${ }^{-1} / \mathrm{mês}^{-1}$ ), representando $27,6 \%$ a menos do que no ambiente natural. Já na estufa sombreada (média de 11,2 frutos planta ${ }^{-1}$ $/$ mês $\left.^{-1}\right)$, não diferiu estatisticamente do ocorrido no ambiente natural de cultivo.

$\mathrm{Na}$ estufa ocorreu a maior quantidade de frutos carpeloides, chegando a ultrapassar em 453,2 $\%$ a média do ambiente natural de cultivo. No entanto, foi também na estufa que teve lugar a máxima expressão de frutos normais, alcançando padrão comercial (59,2\% acima do ambiente natural). Por conseguinte, registrou-se na estufa maior produção de frutos aptos para a comercialização (MARTELLETO et al. (2008).

Nota-se, portanto, que nos ambientes sombreados houve certa restrição ao surgimento de frutos carpeloides e formação de flores estaminadas pelos mamoeiros. No entanto, para frutos normais, sua expressão não obedeceu a esta regra. Assim, a estufa sombreada, com menor incidência de luz e maiores temperaturas, que o ambiente telado (Tabela 3 e Figura 2), proporcionou produção superior de frutos normais se comparado a este último ambiente, embora inferior à produção ocorrida na estufa. $\mathrm{Na}$ estufa, foram registradas, no verão, as maiores temperaturas, com médias superiores a $30{ }^{\circ} \mathrm{C}$, e maior incidência de luz (1211 $\mu$ moles $\left.\mathrm{m}^{-2} \mathrm{~s}^{-1}\right)$, demonstrando que temperaturas mais elevadas e maior luminosidade, dentro dos valores verificados, são imprescindíveis para a melhor formação de frutos de mamoeiro de maior valor comercial.

Observa-se que, tanto na estufa quanto no ambiente natural de cultivo, o máximo número de frutos carpeloides se deu por ocasião da primavera, repercutindo o processo de ontogenia floral ocorrido durante o inverno precedente. Tal resultado seria um indicativo de que temperaturas superiores a $25^{\circ} \mathrm{C}$ no inverno, em conjunto com plantas mais vigorosas, condicionado no ambiente estufa, contribuíram, sobremaneira, para a formação desses frutos anormais, à semelhança do que foi verificado por Awada (1958) e por Almeida et al. (2003) em ambiente natural de cultivo. Já, independentemente do ambiente de cultivo, a maior quantidade de frutos normais deu-se por ocasião das estações de outono e inverno.

Os valores das correlações entre fatores climáticos (temperaturas: máxima, média e mínima, amplitude térmica, radiação fotossinteticamente ativa e umidade relativa do ar) e, mais, caracteres vegetativos do mamoeiro (altura da planta, diâmetro do tronco, $\mathrm{n}^{\underline{0}}$ de folhas emitidas planta ${ }^{-1}, \mathrm{n}^{\underline{0}}$ de folhas funcionais planta $^{-1}$, comprimento da folha-índice e área foliar) quando estimados na fase da ontogenia floral, ou seja, 40 a 56 dias antes da antese (NAKASONE; ARKLE JUNIOR, 1971; NAKASONE, 1980; ARKLE JUNIOR; NAKASONE, 1984; SIPPEL et al., 1989), e as quantidades de flores estaminadas e frutos carpeloides e normais produzidos por planta, são apresentados na Tabela 4.

Os estudos de correlação consubstanciaram a hipótese de que temperaturas mais elevadas e maior vigor da planta representam peso significativo sobre a formação de frutos carpeloides e normais hermafroditas. Por outro lado, o maior nível médio de sombreamento $\left(511,5 \mu\right.$ moles $\mathrm{m}^{-2} \mathrm{~s}^{-1}$ de radiação fotossinteticamente ativa no ambiente mais sombreado em contraste com $1.602 \mu$ moles $\mathrm{m}^{-2} \mathrm{~s}^{-1}$ no ambiente a pleno sol), somado ao efeito do menor vigor vegetativo do ramo produtivo (média de $6,8 \mathrm{~cm}$ no local de inserção do fruto nas plantas manejadas para duas hastes contra 9,1 cm nas plantas sem manejo - dados não publicados), este último propositadamente caracterizado nas plantas de tronco bifurcado, estimularam a formação de flores estaminadas.

A umidade relativa do ar teve pouca influência ou foi ofuscada pelos fatores principais aqui apontados. No entanto, se as temperaturas altas têm correlação positiva com a formação de frutos carpeloides, torna-se difícil explicar a maior frequência do distúrbio na estufa durante a estação de inverno.

Os resultados da presente investigação corroboram as afirmações de Andrade (1980), Papa (1984) e Marin et al. (2003) de que o vigor da planta, acentuado, em condições de estufa, foi preponderante na indução dessa anomalia em mamoeiro. Entretanto, também neste cultivo protegido, houve aumento na produtividade de frutos hermafroditas perfeitos e aptos para a comercialização. Nesse sentido, a maior expressão da carpeloidia foi associada com a maior capacidade produtiva de mamoeiros do grupo 'Solo', no qual se enquadra a cultivar Baixinho- de -SantaAmália. 
Os efeitos da temperatura ambiente sobre a ocorrência de flores estaminadas em plantas hermafroditas de mamoeiro foram já determinados (COU-
TO; NACIF 1999). Porém, não foram encontrados relatos correlacionando níveis de sombreamento e de vigor vegetativo à manifestação dessa anomalia.

\section{Tronco único}

\section{口desbastados $\square$ abortados}

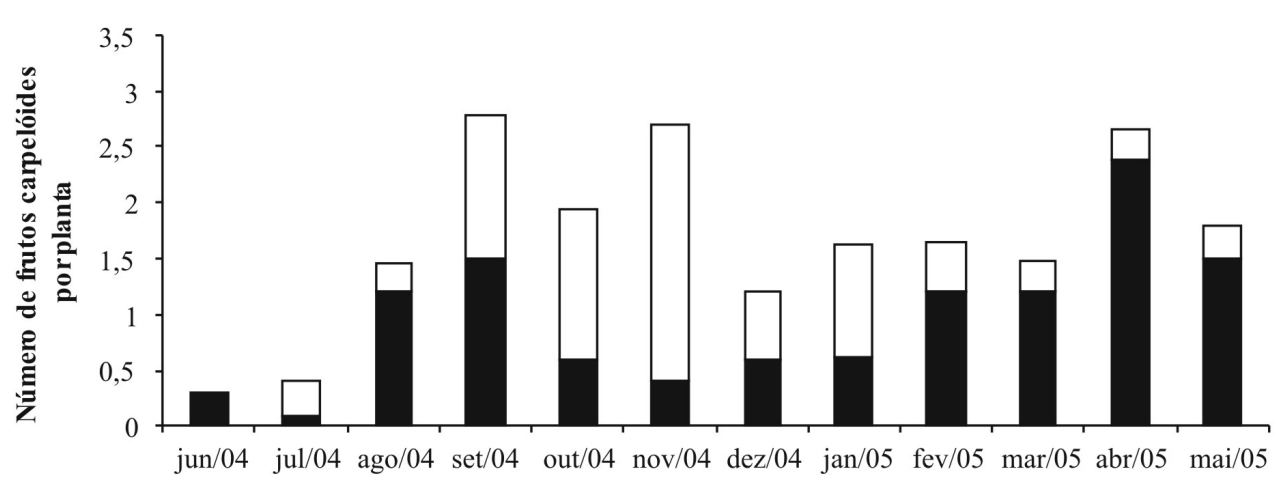

\section{Tronco bifurcado}

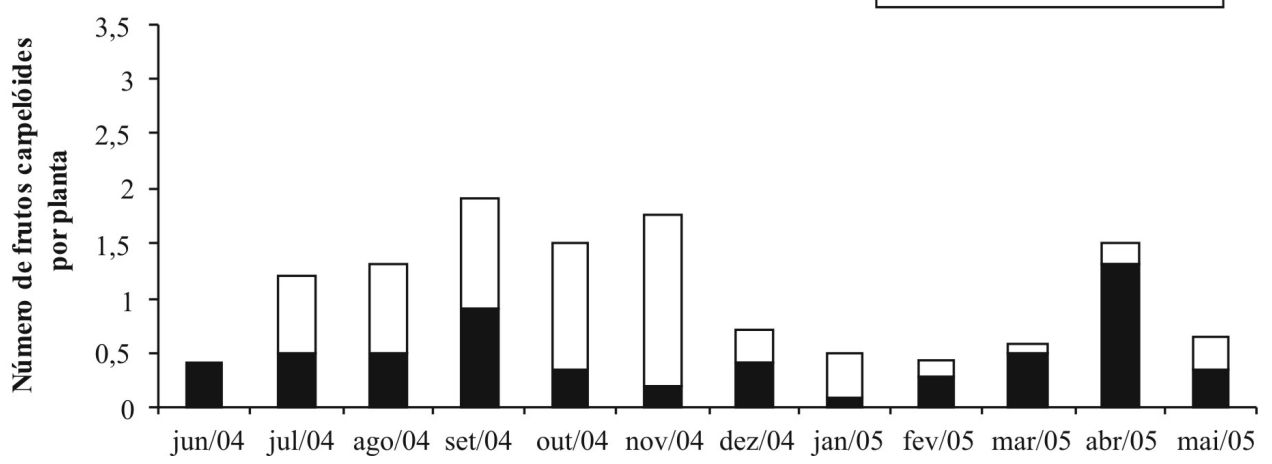

FIGURA 1 - Efeito do tipo de condução das plantas do mamoeiro 'Baixinho- de- Santa -Amália' sobre o número médio de frutos carpeloides por planta, durante o primeiro ano de produção orgânica (Seropédica-RJ). 


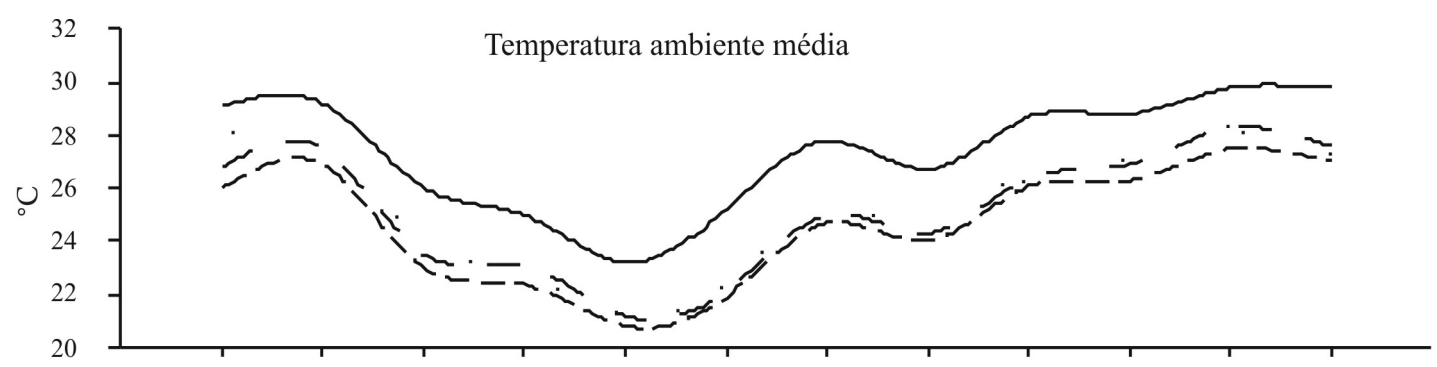

Amplitude térmica
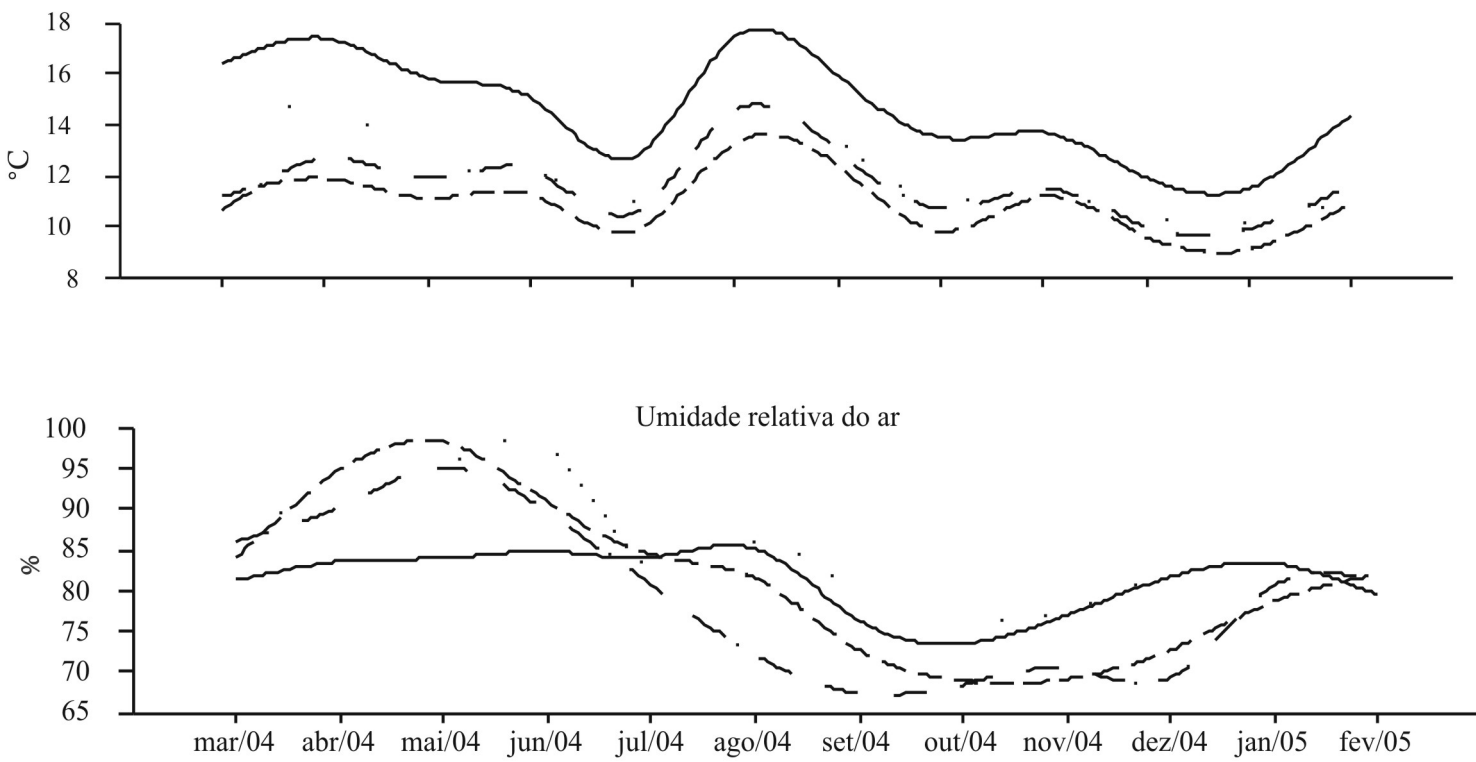

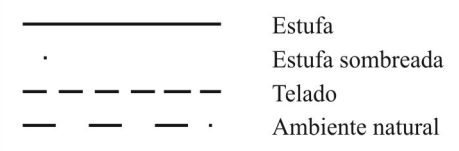

FIGURA 2 - Valores médios mensais da temperatura ambiente, amplitude térmica e umidade relativa do ar, registrados em cada ambiente de cultivo orgânico do mamoeiro (Seropédica-RJ). 
TABELA 1- Efeito da bifurcação artificial do tronco sobre o número de flores estaminadas e frutos carpeloides normais por mamoeiro hermafrodita 'Baixinho-de-Santa-Amália', no decorrer do primeiro ano de produção em cultivo orgânico (Seropédica-RJ).

\begin{tabular}{|c|c|c|c|c|c|c|}
\hline \multirow{2}{*}{$\begin{array}{l}\text { Mês/ } \\
\text { anoo }\end{array}$} & \multicolumn{2}{|c|}{ № de flores estaminadas planta ${ }^{-1}$} & \multicolumn{2}{|c|}{ № Frutos carpeloides planta $^{-1}$} & \multicolumn{2}{|c|}{ № Frutos normais planta $^{-1}$} \\
\hline & Tronco único & Tronco bifurcado & Tronco único & Tronco bifurcado & Tronco único & Tronco bifurcado \\
\hline jun/04 & $0,66 \mathrm{a}^{1}$ & $1,08 \mathrm{a}$ & $0,31 \mathrm{a}^{1}$ & $0,44 a$ & $10,1 \mathrm{a}$ & $12,2 \mathrm{a}$ \\
\hline $\mathrm{jul} / 04$ & $0,76 \mathrm{a}$ & $0,32 \mathrm{a}$ & $0,38 \mathrm{a}$ & $1,06 \mathrm{a}$ & $18,7 \mathrm{a}$ & $13,2 \mathrm{a}$ \\
\hline ago/04 & 0 & 0 & $1,52 \mathrm{a}$ & $1,15 \mathrm{a}$ & $14,3 \mathrm{a}$ & $15,4 \mathrm{a}$ \\
\hline set/04 & $0,04 \mathrm{a}$ & $0,11 \mathrm{a}$ & $3,17 \mathrm{a}$ & $1,90 b$ & $11,8 \mathrm{a}$ & $12,5 \mathrm{a}$ \\
\hline out $/ 04$ & $0,48 \mathrm{a}$ & $0,51 \mathrm{a}$ & $2,27 \mathrm{a}$ & $1,52 b$ & $12,6 \mathrm{a}$ & $13,0 \mathrm{a}$ \\
\hline nov/04 & $1,33 b$ & $3,66 \mathrm{a}$ & $3,18 \mathrm{a}$ & $1,75 \mathrm{a}$ & $8,7 \mathrm{a}$ & $7,3 b$ \\
\hline $\operatorname{dez} / 04$ & $4,83 b$ & $9,67 \mathrm{a}$ & $1,35 \mathrm{a}$ & $0,81 \mathrm{a}$ & $10,3 \mathrm{a}$ & $7,8 \mathrm{~b}$ \\
\hline $\mathrm{jan} / 05$ & $10,09 b$ & $16,28 \mathrm{a}$ & $1,79 \mathrm{a}$ & $0,62 \mathrm{a}$ & $7,1 \mathrm{a}$ & $5,1 b$ \\
\hline $\mathrm{fev} / 05$ & $21,44 b$ & $31,92 \mathrm{a}$ & $1,71 \mathrm{a}$ & $0,48 b$ & $6,1 \mathrm{a}$ & $5,5 \mathrm{a}$ \\
\hline $\mathrm{mar} / 05$ & $34,88 \mathrm{~b}$ & $57,76 a$ & $1,54 \mathrm{a}$ & $0,71 \mathrm{a}$ & $10,4 \mathrm{a}$ & $6,7 b$ \\
\hline $\mathrm{abr} / 05$ & $14,86 \mathrm{~b}$ & $40,42 \mathrm{a}$ & $2,67 \mathrm{a}$ & $1,56 a$ & $12,9 \mathrm{a}$ & $14,2 \mathrm{a}$ \\
\hline mai/05 & $19,16 \mathrm{~b}$ & $45,26 \mathrm{a}$ & $1,83 \mathrm{a}$ & $0,73 \mathrm{a}$ & $12,8 \mathrm{a}$ & $14,0 \mathrm{a}$ \\
\hline Média & 9,04b & $17,25 \mathrm{a}$ & $1,81 \mathrm{a}$ & $1,06 b$ & $11,3 a$ & $10,6 a$ \\
\hline $\begin{array}{c}\text { Efeito } \\
(\%)\end{array}$ & - & 76,7 & - & $-41,4$ & - & $-6,2$ \\
\hline
\end{tabular}

${ }^{1}$ Médias seguidas pela mesma letra nas linhas não diferem entre si ,pelo teste de Tukey, ao nível de 5\% de probabilidade.

TABELA 2 - Efeito do tipo de ambiente protegido sobre o número de flores estaminadas e frutos carpeloides e frutos normais por mamoeiro hermafrodita 'Baixinho-de-Santa- Amália', durante o primeiro ano de produção em cultivo orgânico (Seropédica-RJ).

\begin{tabular}{|c|c|c|c|c|c|c|}
\hline \multicolumn{7}{|c|}{ № frutos carpeloides planta ${ }^{-1} /$ mês $^{-1}$} \\
\hline & Estufa & Estufa sombreada & Telado & Ambiente natural & DMS & $\mathrm{CV}(\%)$ \\
\hline Média & $4,23 \mathrm{a}^{1}$ & $0,57 \mathrm{~b}$ & $0,19 \mathrm{c}$ & $0,76 b$ & 0,3 & 62,3 \\
\hline Efeito (\%) & 453,2 & $-25,9$ & $-75,5$ & - & & \\
\hline \multicolumn{7}{|c|}{ № médio de flores estaminadas planta ${ }^{-1} / \mathrm{mês}^{-1}$} \\
\hline & Estufa & Estufa sombreada & Telado & Ambiente natural & DMS & $\mathrm{CV}(\%)$ \\
\hline Média & $10,7 \mathrm{~b}$ & $18,2 \mathrm{a}$ & $12,2 b$ & $11,4 \mathrm{~b}$ & 3,8 & 41,1 \\
\hline Efeito $(\%)^{2}$ & $-5,9$ & 59,6 & 6,8 & - & & \\
\hline \multicolumn{7}{|c|}{ № frutos normais planta ${ }^{-1} / \mathrm{mês}^{-1}$} \\
\hline & Estufa & Estufa sombreada & Telado & Ambiente natural & DMS & $\mathrm{CV}(\%)$ \\
\hline Média & $15,6 \mathrm{a}$ & $11,2 b$ & $7,1 \mathrm{c}$ & $9,8 b$ & 1,7 & 20 \\
\hline Efeito (\%) & 59,2 & 14,3 & $-27,6$ & - & & \\
\hline
\end{tabular}

${ }^{1}$ Médias seguidas pela mesma letra nas linhas não diferem entre si ,pelo teste de Tukey, ao nível de $5 \%$ de probabilidade; ${ }^{2}$ Efeito dos ambientes protegidos em relação ao ambiente natural de cultivo. 
TABELA3 - Radiação fotossinteticamente ativa $\left(\mu\right.$ moles $\left.\mathrm{m}^{-2} \mathrm{~s}^{-1}\right)$ nos diferentes ambientes de cultivo orgânico do mamoeiro, em dias de sol pleno (Seropédica-RJ).

\begin{tabular}{ccccc}
\hline Horário de medição & Estufa & Estufa sombreada & Telado & Ambiente natural \\
\hline $8 \mathrm{~h}$ & 1080 & 499 & 577 & 1569 \\
$10 \mathrm{~h}$ & 1211 & 532 & 831 & 1639 \\
$12 \mathrm{~h}$ & 1019 & 510 & 989 & 1607 \\
$14 \mathrm{~h}$ & 1022 & 505 & 844 & 1591 \\
Média & $\mathbf{1 0 8 3}$ & $\mathbf{5 1 1 , 5}$ & $\mathbf{8 1 0 , 3}$ & $\mathbf{1 6 0 2}$ \\
\hline Interceptação média & 32,4 & 68,1 & 49,4 & - \\
da radiação solar & & & & \\
\hline
\end{tabular}

TABELA 4 - Coeficientes de correlação linear (r) entre variáveis climáticas ou ligadas ao desenvolvimento vegetativo do mamoeiro 'Baixinho-de-Santa-Amália' e a formação de flores estéreis e frutos carpeloides e normais, em diferentes ambientes de cultivo orgânico (Seropédica-RJ).

\begin{tabular}{|c|c|c|c|}
\hline Variável & Frutos carpeloides & Flores estaminadas ${ }^{1)}$ & Frutos normais \\
\hline Temperatura máxima & $0,61 * *$ & $-0,11$ & $0,51 * *$ \\
\hline Temperatura média & $0,61 * *$ & $-0,1$ & $0,52 * *$ \\
\hline Temperatura mínima & $0,50 * *$ & $-0,09$ & $0,49 * *$ \\
\hline Amplitude térmica & $0,60 * *$ & $-0,11$ & $0,49 * *$ \\
\hline Radiação Fotossinteticamente Ativa & $0,11 * *$ & $-0,26^{*}$ & $0,05 * *$ \\
\hline Umidade relativa do ar & $-0,08 * *$ & 0,19 & $0,09 * *$ \\
\hline Altura da planta & $0,24 * *$ & $-0,08$ & $0,37 * *$ \\
\hline DTLIFC ${ }^{2)}$ & $0,47 * *$ & $-0,37 * *$ & $0,37 * *$ \\
\hline № de folhas emitidas planta ${ }^{-1}$ & $0,04 * *$ & $0,28 * *$ & $0,19 * *$ \\
\hline № de folhas funcionais planta ${ }^{-1}$ & $0,03 * *$ & $0,47 * *$ & $-0,14 * *$ \\
\hline Comprimento da folha-índice & $0,43 * *$ & 0,01 & $0,33 * *$ \\
\hline Área foliar & $0,36 * *$ & $-0,28 * *$ & $0,24 * *$ \\
\hline
\end{tabular}

1) Valores de correlação linear de Pearson entre 96 plantas versus as 12 médias mensais das variáveis; ${ }^{2)} \mathrm{DTLIFP}=$ diâmetro do tronco no local de inserção dos frutos carpeloides; * $\mathrm{r}$ de $+0,20$ a $+0,26$ ou de $-0,20$ a $-0,26=$ significativo a $5 \%$ de probabilidade; ** $r>0,26$ ou $<-0,26=$ significativo a $1 \%$ de probabilidade.

\section{CONCLUSÕES}

O mamoeiro 'Baixinho de Santa Amália' quando tem o seu tronco principal bifurcado reduz a formação de frutos carpelóides e, por outro lado, estimula maior formação de flores fêmeas estéreis. No entanto, a prática da bifurcação do tronco não influencia a freqüência de frutos normais. Durante a primavera (setembro a dezembro), e notadamente na estufa, ocorre o maior número de frutos carpeloides por planta, os quais correlacionam-se às temperaturas mais elevadas, à maior amplitude térmica e ao maior vigor vegetativo da planta. Já, a maior ocorrência de flores estaminadas em mamoeiro está correlacionada às temperaturas elevadas, baixa luminosidade e menor vigor vegetativo da planta. As mesmas condições ambientais e fenológicas favoráveis à carpeloidia au- mentam a quantidade de frutos normais, contribuindo assim, positivamente, para a maior produtividade do mamoeiro.

\section{AGRADECIMENTOS}

À UFRRJ, particularmente ao Curso de PósGraduação em Fitotecnia, Instituto de Agronomia, por disponibilizar os recursos necessários para a construção das estruturas de proteção, e à PESAGRO-RIO/EES, pela indispensável contribuição na montagem das mesmas. 


\section{REFERÊNCIAS}

AlmeidA, D. L. de; RIBEIRO, R. de L. D.; GUERRA, J. G. M. Sistema Integrado de Produção Agroecológica:"Fazendinha Agroecológica Km 47". In: SIMPÓSIO DE AGRICULTURA ECOLÓGICA, 2., ENCONTRO DE AGRICULTURA ORGÂNICA, 1., 1999, São Paulo. Anais... Guaiba: Agropecuária, 1999. p.153-159.

ALMEIDA, F.T. de; MARINHO, C.S.; SOUZA, E.F.de; GRIPPA, S. Expressão sexual do mamoeiro sob diferentes lâminas de irrigação na região Norte Fluminense. Revista Brasileira de Fruticultura, Jaboticabal, v.25 n.3, p.383-385. 2003.

ANDRADE, V. de M. O mamoeiro: taxonomia e morfologia. In: SIMPÓSIO BRASILEIRO SOBREA CULTURA DO MAMOEIRO, 1., 1980, Jaboticabal. Anais... Jaboticabal: UNESP, 1980. p.61-69.

ARKLE JUNIOR, T.D.; NAKASONE, H.Y. Floral differentiation in the hermaphroditic papaya. HortScience, Alexandria, v.19, n.6, p.832-834. 1984.

AWADA, M. Relationships of minimum temperature and growth rate with sex expression of papaya plants (Carica papaya L.). Honolulu: University of Hawaii, 1958. 16p. (Technical Bulletin, 38).

COSTA, A. de F.S.; PACOVA, B.E.V. Caracterização de cultivares, estratégias e perspectivas do melhoramento genético do mamoeiro. In: MARTINS, D. dos S.; COSTA, A. de F.S. (Ed.). A cultura do mamoeiro: tecnologia de produção. Vitória: Incaper, 2003. p.57-102.

COUTO, F.A.D.; NACIF, S.R. Hibridação em mamão. In: BORÉM, A. (Ed.). Hibridação artificial de plantas. Viçosa: UFV, 1999. p.307-329.

DANTAS, L.L.D.; DANTAS, A.C.V.L.; LIMA, J.F. Mamoeiro. In: BRUCKNER, C.H. (Ed.). Melhoramento de fruteiras tropicais. Viçosa: UFV, 2002. p.309-349.

DEFAVARI, D.; MORAES, L.A.C. Fisiologia da floração. In: CASTRO, P.R.C.; SENA, J.O.A.; KLUGE, R.A. (Ed.). Introdução à fisiologia do desenvolvimento vegetal. Maringá: Eduem, 2002. p.191-210.

FERNANDES, M. do C. de A. O biofertilizante Agrobio. A Lavoura, Rio de Janeiro, v.103, n.634, p.42-43, 2000.
LASSOUDIÈRE, A. Le papayer. Fruits, Paris, v.23, n.11, p.585-596, 1968.

MARIN, S. L. D.; YAMANISHI, O. K.; MARTELLETO, L. A P.; IDE, C. D. Hibridação do mamão. In: MARTINS, D. dos S. (Ed.). Papaya Brasil: qualidade do mamão para o mercado interno. Vitória: Incaper, 2003. p.175-220.

MARTELLETO, L.A.P.; RIBEIRO, R.L.D; SUDOMARTELLETO, M.; VASCONCELLOS, M.A.S.; MARIN, S.L.D.; PEREIRA, M.B. Cultivo orgânico do mamoeiro 'Baixinho-de-Santa-Amália' em diferentes ambientes de proteção. Revista Brasileira de Fruticultura, Jaboticabal, v.30, p.662-666, 2008.

MING, R.; YU, Q.; MOORE, P.H. Sex determination in papaya. Seminars in Cell \& Developmental Bilogy, Paris, v.18, n.3, p.401-408, 2007.

NAKASONE, H. Y. Melhoramento de mamão no Havai. In: SIMPÓSIO BRASILEIRO SOBRE A CULTURA DO MAMOEIRO, 1., 1980, Jaboticabal. Anais... Jaboticabal: FCAV/UNESP, 1980. p. 275-287.

NAKASONE, H. Y.; ARKLE JUNIOR, T.D. Development of intra-ovarian ovaries in Carica papaya L. Journal of the American Society for Horticultural Science, Alexandria, v.96, n.5, p.550-553, 1971.

PAPA, E.G. Produção e qualidade de frutos de mamoeiro (Carica papaya L.) cultivado em casa de vegetação e em campo com irrigação por gotejamento ou jato pulsante. 1984. 39f. Dissertação (Mestrado) - Faculdade de Ciências Agrárias e Veterinárias, Universidade Estadual Paulista, Jaboticabal, 1984.

PIMENTEL-GOMES, F. Curso de estatística experimental. Piracicaba: ESALQ, 2000. 477p.

RONSE, L., SMETS, E. The floral development and anatomy of Carica papaya (Caricaceae). Canadian Journal of Botany, Ottawa, v.77, p.582-598, 1999.

SIPPEL, A.; CLAASSENS, N.; HOLTZHAUSEN, L. Floral differentiation and development in Carica papaya L. cultivar 'Sunrise Solo'. Journal of the American Society for Horticultural Science, Alexandria, v.40, p.23-33. 1989.

STEEL, R.G. D.; TORRIE, J. H. Principles and procedures of statistics: a biometrical approach. New York: McGraw-Hill Book Company, 1980. $683 \mathrm{p}$. 